\title{
Contextos, mediações e produção de sentidos: uma abordagem conceitual e metodológica em comunicação e saúde
}

DOI: $10.3395 /$ reciis.v3i3.280pt

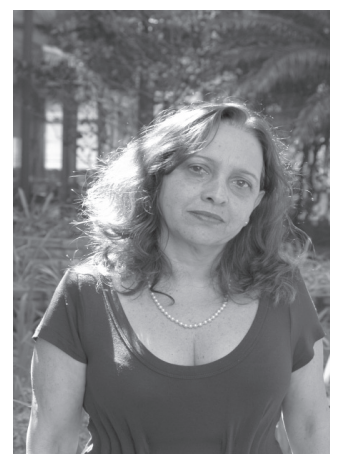

\section{Inesita Soares de Araújo}

Instituto de Comunicação e Informação Científica e Tecnológica em Saúde-Fiocruz, Rio de Janeiro, Brasil

inesita@icict.fiocruz.br

\section{Resumo}

O artigo discute as idéias de contexto, mediação e produção de sentidos, à luz da prática metodológica do Laboratório de Pesquisa em Comunicação e Saúde - Laces. A partir de seu referencial teórico e suas pesquisas, conferindo especial atenção aos métodos utilizados, aporta, esclarece e exemplifica os conceitos de lugar de fala, hibridismo, centro e periferia discursivos, concorrência discursiva, comunidade discursiva e lugar de interlocução. Partindo da premissa de que o processo de produção das realidades é intersticial, porque ocorre na articulação (tensa ou sinérgica) de duas ou mais realidades e que essa articulação é produto e produz processos de apropriação, defende que os métodos mais correntes hoje no campo da comunicação não conseguem apreender as múltiplas dimensões dos dinâmicos objetos de pesquisa, formados basicamente por fluxos e relações. Em contraposição, apresenta pesquisas que inovaram na condução metodológica, experimentando combinações de procedimentos ou utilizando referenciais e procedimentos que habitualmente não são usados como método de pesquisa.

\section{Palavras-chave}

comunicação e saúde; metodologia de pesquisa; contexto; mediações; lugar de interlocução

\section{Introdução}

Um tema que hoje se apresenta recorrentemente não só à área das Ciências da Informação e da Comunicação, mas às Ciências Sociais, de um modo geral é o dos espaços intersticiais, das linhas de fronteira que, ao contrário do que muitos pensam, não é onde tudo acaba e sim onde se inaugura um outro lugar, compósito, que privilegia as superfícies de contato e as novas realidades que dali emergem.
No campo das idéias, esse lugar já vem sendo identificado e delineado, em geral recebendo o nome de transdisciplinaridade, que designa a natureza do conhecimento transversal que se constrói a partir da convergência e conjugação de saberes distintos. Neste enfoque, ganham sentido outros termos correlatos, migração e apropriação de conceitos. Dizer que "ganham sentido", porém, já expressa que esses termos vêm de outro campo de saber e são "apropriados" pelas Ciências da Informação e da 
Comunicação. São “tornados próprios”, principal indicador de que ali se forma uma nova realidade.

Migração é um conceito da geografia, designando, como se sabe, o movimento de populações que, levando consigo uma cultura e uma história, vão construir outras culturas e histórias na interface com as da sociedade que as acolherá. O sentido de migração de conceitos, portanto, traz consigo a gênese da palavra migração, com sua predestinação ao novo, ao outro.

Nos estudos culturais, migração está relacionada a hibridismo, que entre outras abordagens, pode ser entendido como processos socioculturais que produzem a combinação de estruturas ou práticas preexistentes, gerando novas estruturas, objetos e práticas (CANCLINI, 2000); mas também pode referenciar processos estratégicos de relocalização e reinscrição no espaço social e discursivo (ALBERT, 1995; BHABHA, 1998; ARAÚJO, 2002). De qualquer modo nos traz sempre a idéia de uma realidade de interface, produzida em espaços de fronteira e possibilitada por movimentos migratórios e de apropriação.

Não é fácil, no âmbito acadêmico e científico, cruzar essas linhas demarcatórias e abrir mão da nossa prática de pensar de forma compartimentada, setorial, departamental. Passos largos têm sido dados neste sentido e, embora ainda se necessite muito investimento no tema, publicações e eventos científicos têm feito deste seu objeto de atenção. Porém, quando nos remetemos ao domínio das práticas e relações sociais, que são o campo empírico de nossas pesquisas, deparamo-nos com uma problemática bem mais complexa.

A compartimentação dos saberes nos leva a compartimentar a prática social: segmentamos a população e, em cada "nicho" particular segmentamos suas práticas. Esse "esquartejamento" é complementado, contraditoriamente, pelo movimento oposto, o da homogeneização desses segmentos. Assim, temos “jovens", "índios”, "mulheres", "trabalhadores da saúde", faixas etárias, perfis sócio-demográficos..., categorias que, se facilitam a coleta e tratamento dos dados de uma pesquisa, produzem o efeito nefasto de fazer perder de vista as múltiplas possibilidades que cada uma delas encerra.

A realidade nos mostra que a prática social é feita de heterogeneidade; as palavras- chave são pluralidade e diversidade. Indo além, as realidades vividas pelos grupos sociais não são movimentos com características pré-definidas, facilmente observáveis e apreensíveis. Pelo contrário, são fluidas, de natureza situacional, relacional, sempre em movimento e não admitindo enquadramentos fixos e definitivos. O processo de produção das realidades é intersticial, porque ocorre na articulação (tensa ou sinérgica) de duas ou mais realidades. Essa articulação, dialeticamente, é produto e produz processos de apropriação: as pessoas e grupos sociais continuamente tornam próprio o que lhes é ofertado concretamente ou discursivamente pelos demais grupos e pelas instituições.

Desses processos sociais e do que eles produzem sabemos pouco, ainda. Os métodos consagrados de pesquisa advindos da ciência política, da antropologia, da sociologia, lingüística ou das ciências matemáticas, que são a base tradicional das pesquisas em comunicação, permitem acessar alguns aspectos ou dimensões das realidades sociais, mas foram fundados em pilares teóricos que não percebiam ainda essa complexidade. Por isto, têm sido insuficientes para dar conta de conceitos analíticos hoje irrecusáveis para nós, como intertexto, polifonia, articulação, mercado simbólico, produção e negociação de sentidos, principalmente quando aplicados a uma sociedade heterogênea e multifacetada como a nossa. Eles têm sido insuficientes, sobretudo, em processos de produção do conhecimento que pretendem amplificar as vozes habitualmente silenciadas ou que são levadas a clandestinizar seus próprios discursos, em favor de uma inscrição mais vantajosa na cena social. Esses procedimentos não dão conta de objetos fluidos e em constante movimento, como as relações comunicativas. Nossos objetos pedem métodos que favoreçam uma compreensão desses movimentos de produção social dos sentidos dos vários setores e segmentos da sociedade, dos seus modos de estar no mundo e agir sobre o mundo.

Esta afirmação traduz uma das questões que vêm sendo trabalhadas pelo Laces - Laboratório de Pesquisa em Comunicação e Saúde. A configuração do Laces e seus modos de abordar este e outros temas serão objeto deste trabalho.

\section{Um lugar de fala - o Laces}

O lugar de fala de cada pessoa ou grupo, que é dado histórica e institucionalmente, circunscreve o âmbito de suas atenções, propostas e modos de agir sobre o mundo. O lugar de onde falamos é o Laces, que por sua vez tem seu lugar definido pela inscrição no Icict - Instituto de Comunicação e Informação Científica e Tecnológica, unidade da Fundação Oswaldo Cruz que tem por missão desenvolver a pesquisa, o ensino e oferecer serviços no campo da Informação e da Comunicação em Saúde, nas especificidades desses domínios do conhecimento, mas, sobretudo, na construção e consolidação dos elementos de interface.

No Ensino, o Icict oferece cursos de Mestrado e Doutorado em Informação e Comunicação em Saúde; cursos de Especialização em Comunicação e Saúde e em Informação Científica e Tecnológica; um curso de Atualização em Análise Espacial e Geoprocessamento em Saúde, além de outros de curta duração. A Pesquisa é desenvolvida em três laboratórios, Informação em Saúde, Comunicação em Saúde e Ciência, Tecnologia e Inovação em Saúde. Nos Serviços, entre outros, coordena uma rede de sete bibliotecas, dispõe de um núcleo de produção e distribuição de audiovisuais e um núcleo de experimentação de tecnologias interativas.

No Laces pesquisamos e ensinamos sobre Comunicação e Saúde. Nossa trajetória reflete, em alguma medida, a constituição desse campo. Embora os vínculos entre as duas áreas do conhecimento possam ser localizados há mais de um século, podemos dizer, tomando a saúde como lugar de observação e fala, que apenas ao final dos anos 80 começou a configurar-se um campo, no sentido 
bourdineano (BOURDIEU, 1989, 1997), como espaço multidimensional, formado por teorias, metodologias, políticas, práticas, instituições, interesses, acordos e lutas. Ao final daquela década, no movimento da construção no país de um novo sistema de saúde (o Sistema Único de Saúde - SUS), a articulação entre Comunicação e Saúde passou por um processo de problematização e renovação, a partir da crítica produzida por um grupo de profissionais de instituições de saúde. Esse movimento produziu, entre outros cenários científicos, acadêmicos e políticos, a abertura, pelos órgãos de fomento científico, de linhas de financiamento voltadas para o tema.

A origem do Laces situa-se nesse contexto, inicialmente como um Núcleo de Pesquisas do então Centro de Informação Científica e Tecnológica, ainda em 2003. No momento em que o Centro, em reconhecimento por sua ação efetiva na área de Ensino e Pesquisa, foi alçado a Instituto - o Icict, o Núcleo recebeu a configuração de Laboratório, vinculado à Vice-diretoria de Pesquisa e Ensino. Conta atualmente com oito pesquisadores, sendo quatro doutores, dois doutorandos e dois mestres.

O Laces lidera, no Conselho Nacional de Desenvolvimento Científico e Tecnológico (CNPq), o grupo de pesquisa em Comunicação e Saúde, com as linhas de pesquisa "Comunicação nas políticas públicas de saúde" e "Saúde e mídia". A primeira acolhe estudos sobre políticas, práticas e estratégias de comunicação no campo da saúde, considerando os princípios constitucionais do SUS de eqüidade, universalidade e integralidade, assim como as diretrizes de descentralização e participação social. A segunda reúne pesquisadores que, tomando o direito à comunicação como inerente ao direito à saúde, estudam e desenvolvem metodologias de análise sobre os dispositivos pelos quais a mídia participa da produção social dos sentidos da saúde e como o uso das tecnologias de comunicação pode favorecer a ampliação ou restrição desse direito.

A multidimensionalidade da comunicação e a heterogeneidade dos processos sociais nos impõem desafios, que buscamos enfrentar: 1) descobrindo, apropriando e mesmo elaborando conceitos que nos aproximem dessa realidade multifacetada; e 2) experimentando e desenvolvendo métodos que permitam apreensão dos nossos objetos (processos sociais multidimensionais, fluxos, relações). Isto tem sido feito pelos seus pesquisadores, que trazem histórias diferenciadas de vida profissional, acadêmica e científica, que produzem escolhas distintas quanto a temas, objetos, autores, métodos. Portanto, se o que será apresentado nos próximos tópicos, corresponde sem dúvida à base teórico-metodológica mais antiga, por isto mesmo mais consolidada do Laces, mas traduz apenas um certo número de interfaces e contextos.

\section{Uma aproximação teórico-conceitual da realidade}

Do arcabouço teórico do Laces, que apresenta uma permanente abertura para outras possibilidades, destacamos aqui alguns conceitos entre os estruturantes da nossa análise social e prática metodológica, particular- mente contexto, produção social de sentidos, mediações, concorrência discursiva, comunidade discursiva e lugar de interlocução, que referenciam dimensões da nossa concepção de comunicação. É com esta concepção que iniciamos este tópico.

A comunicação é percebida por nós como um processo baseado na interlocução e na negociação de sentidos. Supõe um fluxo contínuo de informação e saberes entre pessoas e comunidades discursivas (MAINGUENEAU, 1993; ARAÚJO, 2000), desfazendo a polaridade produção-recepção característica dos modelos informacionais. Esses fluxos são multidirecionais e percorrem redes materiais e virtuais, sendo determinados por contextos de naturezas diversas. Por esta perspectiva, a comunicação opera como um mercado, no qual comunidades discursivas negociam bens simbólicos - seu modo de perceber e classificar o mundo e a sociedade, em busca do poder simbólico (BOURDIEU, 1989), o poder de constituir a realidade. ${ }^{1}$

Este enfoque da comunicação como mercado simbólico baseia-se na articulação do modelo produtivo de Verón (1980) à teoria do poder simbólico de Bourdieu (1989), subsidiado pela perspectiva da língua como arena dos embates sociais (BAKHTIN, 1988) e pela microfísica do poder (FOUCAULT, 1982).

Uma mesma realidade empírica pode ser percebida de vários modos e, assim sendo, não será mais a mesma realidade. A concepção de comunicação modela nosso olhar sobre a prática social. Onde as teorias e modelos mais conhecidos vêem apenas o desafio de se comunicar bem com seus interlocutores, podemos perceber um espaço discursivo, de natureza concorrencial, onde comunidades discursivas disputam os sentidos sobre temas do seu interesse; nesse mercado circulam e são apropriados discursos que buscam alianças ou confrontos em busca do poder de fazer ver e fazer crer (BOURDIEU, 1989). Onde teorias percebem a língua como um repertório de códigos, portanto transferíveis e decodificáveis, nossa perspectiva acolhe a noção bakhtiniana de língua como espaço de acordos e conflitos, portanto estruturante das relações de poder. A busca de fórmulas comunicativas eficazes, própria dos modelos de natureza transferencial, cede lugar a um processo de conhecimento do funcionamento discursivo das relações. Desiste-se da pretensão de repassar significados e admite-se que o sentido é instável e negociável (ARAÚJO, 2002).

De um ponto de vista mais operacional, que favorece as formulações metodológicas, podemos dizer que a comunicação é o processo de produção, circulação e apropriação de bens simbólicos. Evitamos, assim, considerar os textos como produtos tratados de forma autônoma, (próprio dos modelos mais correntes, focados na produção), valorizando-se os processos de circulação e apropriação, que são instâncias estratégicas e definidoras dos sentidos sociais.

No seu esforço para avançar no pensamento sobre a comunicação e se aproximar dessas instâncias, o LACES tem recorrido à Semiologia dos Discursos Sociais (PINTO, 1994). Esta abordagem nos oferece três postulados que 
têm sido de grande valia para a compreensão dos processos "fronteiriços", além de propiciar perceber os discursos não apenas como espaço e agente da reprodução do status quo, mas da luta política e da transformação social.

O postulado da heterogeneidade enunciativa (idem) dispõe que todo texto é um conjunto de vozes (polifonia) que se exprimem, se articulam, se confrontam, se legitimam ou se desqualificam mutuamente e a esta rede interativa entre enunciados, entre textos, entre textos e contextos podemos chamar de dialogismo (BAKHTIN, 1988). O dialogismo é a essência do postulado da semiose infinita (PINTO, 1994), que descreve o movimento incessante dos sentidos, através de uma rede remissiva que é acionada em cada enunciação.

Se um texto é polifônico, o discurso - conjunto de textos articulados numa prática, a prática discursiva também assim se apresenta. Aprendemos com Bakhtin, porém, que as vozes correspondem a "sotaques" sociais, que por sua vez correspondem a interesses e posições distintos na topografia social; essas vozes se defrontam e se confrontam na língua, numa luta pelo predomínio discursivo. Então, discursos são o espaço primeiro no qual se dão os embates sociais e se estabelecem as relações de poder.

Por fim, o postulado da economia política do significante (idem), dispondo sobre o processo produtivo dos sentidos sociais, está na base da percepção da existência do mercado simbólico.

Este mercado, porém, não ocorre entre iguais. $\mathrm{O}$ poder de produzir e de fazer circular seus discursos é desigualmente distribuído. Consideramos a existência de um Centro e de uma Periferia discursivos, posições máximas e mínimas de poder na comunicação. Os agentes sociais localizam-se em algum ponto dessa escala de poder, que é sempre situacional, determinado pelas situações específicas de comunicação e desenvolvem estratégias de aproximação com o Centro (ou, no caso do Centro, de manutenção da posição). Às instâncias materiais e simbólicas que promovem esses fluxos, chamamos de "fatores de mediação" e estão sistematizados numa matriz analítica (ARAÚJO, 2002; 2003).

A compreensão desse mercado e de seu jogo de forças fica facilitada pelo conceito de "comunidades discursivas", que designa as pessoas que produzem e fazem circular discursos, que se reúnem em seu nome, neles se reconhecem e por eles são reconhecidos (MAINGUENEAU, 1993; ARAÚJO, 2000). O reconhecimento, que traz inerente a relevante noção de legitimidade (BOURDIEU, 1989), é fundamental na compreensão do papel que estas comunidades ocupam no mercado simbólico. Do ponto de vista metodológico, entre outras vantagens, o conceito de comunidade discursiva permite perceber os discursos do agente situado institucionalmente, os discursos dentro da mesma instituição e os que estão além das estruturas institucionais e evita que se considere as instâncias mediadoras como simples pontos de passagem dos discursos, desprovidos da capacidade de produzir sentidos.

Uma das premissas teóricas das pesquisas do Laces é a da contextualização como condição de produção dos sentidos sociais (PINTO, 1999). Os estudos da linguagem e poder, as teorias da recepção, os estudos culturais e os estudos do discurso, de um modo geral têm reconhecido a necessidade de se perceber os sujeitos e as relações sociais de forma situada, isto é, sendo constituídos num espaço e num tempo que exercem coerções sobre seu modo de ser. Assumimos essa premissa - o discurso é situado e o princípio teórico que lhe é inerente: o sistema produtivo dos discursos é constitutivo dos efeitos que produz. Ao sistema produtivo denominamos contexto, ou, em outros termos, o conjunto de variáveis que possibilitam a existência de uma enunciação, um texto, um discurso, mantendo com eles uma relação dialética de mútua constitutividade.

Percebemos a realidade como produto de vários contextos, cuja articulação promove um efeito de unidade. Em constante movimento e interdependentes, estes contextos são campos de luta simbólica e, como tal, espaços onde os agentes desenvolvem estratégias de manutenção ou transformação da ordem dominante, seja econômica, política, ou discursiva. Nos domínios simbólicos, a interdependência é uma decorrência lógica da interdiscursividade. As linhas que separam os discursos e os contextos de outros são maleáveis, porosas. São fronteiras movediças, deslizantes, podem ser linhas de tensão, mas são sempre espaços de negociação. Destacamos quatro tipos de contextos relevantes para a compreensão dos processos de produção dos sentidos (ARAÚJO, 2000).

O contexto textual (ou co-texto), fala da relação de contigüidade entre textos na mesma superfície espacial ou temporal. A posição dos enunciados em relação aos que lhe são próximos constitui condição de produção dos sentidos possíveis. O potencial de poder simbólico que um texto pode ter depende, então, do co-texto. A palavra-chave aqui é textualidade.

O contexto intertextual também é constituído pelas relações entre textos, mas não dependem da proximidade física: seu efeito se dá pela rede de semiose que é acionada a cada enunciação, que se nutre da memória discursiva. Cada pessoa tem sua rede textual particular, formada pelo acervo que acumulou ao longo da vida, o que faz com que um mesmo texto adquira múltiplos sentidos. A palavra chave aqui é historicidade.

$\mathrm{O}$ contexto existencial diz respeito à posição dos interlocutores como pessoas no mundo, situados num tempo e num espaço particular: sua história de vida, seus grupos de pertença, gênero, classe, idade, sua experiência anterior com o referente de cada ato comunicativo, sua história de relações com as instituições. Em última análise, é o contexto existencial que definirá a rede intertextual e comandará a articulação dos demais contextos. A palavra-chave aqui é prática social.

O contexto situacional referencia o lugar social do qual e no qual os interlocutores desenvolvem suas relações comunicativas e participam da disputa de sentidos. As pessoas ocupam posições na topografia social que, em contato com seus interlocutores, também posicionados, determinam a legitimidade de sua fala e o grau inicial 
de poder a partir do qual ela desenvolve suas estratégias enunciativas. Uma pessoa pode ocupar diferentes posições, dependendo do contexto situacional. Em cada uma exerce um grau diferente de poder em relação ao seu interlocutor, modificando-se a natureza do texto que será produzido e as regras discursivas que presidem o ato de interlocução. A essas posições chamamos de "lugar de interlocução" (ARAÚJO, 2002; 2003). A palavra-chave aqui é, então, lugar de interlocução.

O conceito "lugar de interlocução" resultou de uma reflexão sobre a posição das pessoas, nos modelos teóricos da comunicação, quanto à distribuição do poder de falar. Está, portanto, fortemente associado à teoria do poder simbólico que integra nosso enfoque da comunicação. Analiticamente, é produto da articulação de três outros conceitos: lugar de fala (BENVENISTE, 1989), lugar de leitura (LANDOWSKI, 1992) e terceiro espaço de enunciação (BHABHA, 1998), inserido, porém, no quadro teórico da concorrência discursiva. Metodologicamente, referencia ao mesmo tempo interlocutores, processos e contextos e sua aplicação abrange o circuito produçãocirculação-apropriação.

Por fim, a noção de "contexto" permite relativizar o efeito ideológico de fechamento dos sentidos, entre outras conseqüências trazendo à cena vozes e histórias que podem ser dissonantes e que, habitualmente, não são percebidas ou consideradas. Contexto é, assim, um conceito vital para nós e boa parte dos nossos esforços no Laces têm sido no sentido de traduzi-lo metodologicamente. Mas, tanto no âmbito teórico quanto no metodológico, é impossível falar de contexto sem falar de mediação, sendo eles inseparáveis na prática comunicativa, portanto no processo de produção social dos sentidos.

Mediação é um conceito com múltiplas apropriações e vem sendo bem desenvolvido no âmbito da comunicação, sobretudo pelos Estudos Culturais Latino-Americanos. Um de seus maiores expoentes Jesús Martin-Barbero - tem como pressuposto principal que a comunicação, por ser uma questão de mediações mais do que de meios, ou seja, uma questão de cultura, é uma questão menos de conhecimento e mais de reconhecimento (MARTIN-BARBERO, 1993). O trabalho de Barbero legitima um campo de estudos que articula a comunicação com o ordenamento social e histórico

Guillermo Orozco, outro expoente da teoria das mediações latino-americana, desenvolveu metodologicamente o conceito de Barbero e propôs um modelo de multimediações, no qual são contempladas as individuais, situacionais, institucionais e massmediáticas (OROZCO-GÓMEZ, 1997).

No Laces, agregando essas e outras contribuições e partindo da idéia simples e geral de que mediação é a propriedade exercida pelo elemento que possibilita a conversão de uma realidade em outra (ARAÚJO, 2002), procuramos descobrir novas possibilidades e potencializar sua aplicação nos estudos sobre os processos de produção dos sentidos da saúde. Dentro desse propósito, desenvolvemos uma matriz de fatores de mediação que podem promover ou dificultar o trânsito entre as posições de poder discursivo. Nossa matriz contempla os seguintes fatores: motivações e interesses; relações (pessoais, grupais/comunitárias, institucionais e organizacionais); competências; discursividades (discursos, sistemas de nomeações, paradigmas, teorias e modelos); dispositivos de comunicação (de enunciação, de produção e circulação discursiva, mediações tecnológicas); e leis, normas e práticas convencionadas.

Os processos relacionais costumam ser vistos nas instituições como idealmente harmônicos. No entanto, os cenários onde eles ocorrem são espaços de relações assimétricas e de confronto. As noções de Centro e Periferia, de concorrência discursiva, de hibridismo como estratégia de luta por melhores lugares de interlocução, de mediação e contexto permitem compreender como as Periferias negam ou resistem à homogeneização e outras estratégias de manutenção do status quo do Centro, seja este representado por uma instituição, uma instância governamental, uma estrutura de gestão, métodos e teorias ou modelos de análise e ação. Com esse acervo conceitual, temos a possibilidade de considerar especificidades contextuais, históricas, políticas, geográficas, enunciativas, além de analisar melhor as estratégias periféricas de relocalização e reinscrição no cenário social e discursivo.

\section{Uma aproximação metodológica da realidade}

O Laces tem o permanente interesse em compreender e formular uma análise das políticas, processos e práticas comunicacionais e sua relação com a configuração das relações sociais. O objeto mais constante tem sido, pelas premissas teóricas, a prática discursiva das instituições e de segmentos da população, localizada em temas específicos. As perguntas mais recorrentes, ainda que em constante atualização, são: como se formam os sentidos dominantes na saúde? De que modo pessoas e instituições equilibram forças e disputam poder simbólico na prática social e especificamente na saúde? Por quais modos a população re-significa e se apropria das informações sobre saúde? Como os meios de comunicação participam da formação dos sentidos sociais sobre a saúde? Como se formam as redes de sentido?

Nas nossas pesquisas, apostamos que as pessoas, ocupando sempre diferentes lugares de interlocução, não se apresentam ao consumo simbólico de uma forma homogênea e estável, mas que os movimentos e modos de apropriação (portanto, de produção dos sentidos) vão se constituindo mediante os múltiplos processos interativos. Essas apropriações determinarão modos diferentes de agir sobre a realidade e de encontrar soluções para os problemas de saúde. Apostamos também que a comunicação é um processo permanente de negociação e que não existe uma relação causal e mecânica entre receber e compreender uma mensagem e mudar o comportamento.

Temos dedicado especial atenção à experimentação e desenvolvimento metodológico, motivado pelas lacunas deixadas pelos métodos habitualmente utilizados para aproximação com a realidade estudada. Isto acrescenta 
outra pergunta, definitória de nossas pesquisas: quais os métodos que permitem apreender um maior número de dimensões da prática comunicativa na saúde? Ao mesmo tempo em que fazemos recurso aos métodos clássicos das Ciências Sociais, como entrevistas, buscamos introduzir novos procedimentos e experimentar combinações que permitam ampliar a cobertura das dimensões dos objetos pesquisados e corresponder a conceitos como contexto, mediações, concorrência discursiva, comunidades discursivas, dispositivos de enunciação, circulação e apropriação, que não conseguem ser apreendidos adequadamente nos métodos mais usuais. Selecionamos três pesquisas que podem exemplificar o exposto.

\section{Promoção da saúde e prevenção do HIV/ aids no Município do Rio de Janeiro: uma metodologia de avaliação para políticas públicas e estratégias comunicação}

Tendo como interesse experimentar a combinação de procedimentos que permitissem avançar além das habituais verificações de recall (modalidade de avaliação da comunicação que visa descobrir o que as pessoas lembram e compreenderam das mensagens) e avaliar os modos particulares de atribuição de sentidos sobre a prevenção epidemiológica, tomamos o tema da aids entre adolescentes de áreas pobres o Rio de Janeiro. A proposta metodológica foi associar um processo de mobilização, com o objetivo de obter produtos comunicacionais elaborados pelos jovens, com um método de análise discursiva, que permitiria, através desses produtos, analisar os discursos que compunham seus modos de enfrentamento da aids.

Para a mobilização, optamos pelo método de Toro (1996), que trabalha com as forças orgânicas do segmento estudado e favorece que os vários discursos tenham visibilidade e possam concorrer de forma menos assimétrica. Para Toro, a comunicação se define como a capacidade que uma sociedade tem de fazer circular seus discursos e os de outras sociedades. Assim, ao reconhecer a pluralidade de discursos sociais, favorece a emergência de sentidos nãohegemônicos, ampliando as condições para que os atores sociais se convertam em atores políticos.

Para a análise, optamos pela Análise Social dos Discursos, numa abordagem dos discursos que relaciona texto e contexto, ou seja, analisa os textos contrapostos às suas condições de produção, circulação e apropriação (PINTO, 1999). ${ }^{2}$ A ASD combina a relevância conferida aos dispositivos de enunciação e à historicidade, próprios da vertente francesa de análise de discursos, com a ênfase na pragmática das relações discursivas, mais característica das abordagens de origem anglo-americana. ${ }^{3}$

Fizemos também um mapeamento das fontes e fluxos da comunicação sobre o tema da aids (ARAÚJO, 2006), no âmbito dos segmentos jovens estudados.

Metodologicamente, a combinação de teorias e procedimentos se mostrou produtiva. Permitiu, entre outras coisas, desvelar contextos heterogêneos, pontos de vista socialmente desqualificados e estratégias desviantes (de mimetismo discursivo e clandestinização dos seus próprios discursos, entre outros) dos que, historicamente desprovidos de capitais simbólicos, estão na periferia dos poderes discursivos. Esta realidade costuma ser ocultada pelo efeito ideológico de homogeneização de sujeitos e discursos (PÊCHEUX, 1990), pelo hábito de tratar a população a partir de médias e perfis estatísticos e pelo modelo de comunicação que só considera o grau de decodificação das mensagens.

Esta pesquisa foi realizada entre fevereiro de 2002 e julho de 2003, com apoio financeiro da CN-DST/Aids/ MS e da Unesco.

\section{Pesquisa avaliação da comunicação na prevenção da dengue}

Esta pesquisa partiu do interesse nos processos de produção dos sentidos na prevenção epidemiológica, tendo como premissa que estes sentidos resultam da combinação de vários discursos que emanam de fontes distintas. Também havia o interesse de participar do cada vez mais acirrado debate sobre as relações entre os meios de comunicação e as instituições de saúde.

Tomamos então o caso específico da dengue, doença de caráter epidêmico, e partimos de três perguntas: o que e como a mídia fala da dengue? O que e como as instituições de saúde falam da dengue, nos materiais dirigidos à população? Como a população se apropria dessas falas e como elas repercutem nas práticas preventivas?

A metodologia baseou-se na experimentação associada de procedimentos em geral adotados isoladamente, aplicados em três movimentos distintos e paralelos: monitorando e analisando os dispositivos de enunciação de dois jornais impressos e dois telejornais, selecionados entre os mais lidos e assistidos pela população estudada; analisando os materiais de comunicação (fluxos e conteúdo) que instituições de saúde fizeram circular no período estudado; e obtendo a fala da população sobre a dengue.

A análise foi comparativa, contrapondo-se os discursos midiáticos e institucionais entre si e estes com a fala da população. A Análise Social dos Discursos (PINTO, 1999) foi a opção analítica, associada a duas modalidades de cartografia: a dos fluxos dos materiais institucionais, desde o Ministério da Saúde até a população e a das fontes e fluxos de comunicação sobre a prevenção da dengue, a partir da identificação da própria população.

A metodologia mostrou-se adequada para os fins propostos, permitindo, entre outros resultados, evidenciar similaridades nos dispositivos de enunciação midiáticos e institucionais e sua discrepância em relação aos dispositivos da população.

A pesquisa (2003-2007) teve apoio da Faperj, através do Programa de Desenvolvimento e Inovação Tecnológica em Saúde Pública (PDTSP), da Fiocruz.

\section{Fala, Conselheiro! Análise de estratégias e redes de interesse na XII Conferência Nacional de Saúde}

Nesta pesquisa, experimentamos a utilização combinada de dois métodos de análise de discursos, desenvolvidos em diferentes universidades. O Discurso do 
Sujeito Coletivo (DSC) proposto por Fernando Lefèvre (Faculdade de Saúde Pública/USP), que busca identificar as "idéias centrais" presentes nos vários discursos e assim mapear a constituição de coletivos simbólicos que caracterizam segmentos específicos de atores sociais e políticos (LEFÈVRE \& LEFÈVRE, 2006). E a Análise Social dos Discursos (ASD), desenvolvido por Milton Pinto e seus discípulos (Escola de Comunicação/UFRJ), já referenciada anteriormente neste artigo, que trabalha com a noção de dispositivos de enunciação e relaciona texto, intertexto e contextos de produção, circulação e apropriação.

Como objeto, tivemos as estratégias de comunicação utilizadas por conselheiros na XII Conferência Nacional de Saúde 4 . Como objetivos, além da experimentação metodológica, mapear as redes de interesses representados na Conferência e identificar as estratégias de comunicação dos delegados.

A combinação de métodos, além de possibilitar uma análise mais realista das possibilidades e limites dessa articulação metodológica, produziu resultados que não seriam possíveis com outro referencial. Entre eles, destacamos a constatação da presença de múltiplos lugares de fala concorrendo ao nível da enunciação e levando ao privilegiamento de determinados grupos em detrimento do coletivo representado. Outro resultado muito interessante foi evidenciar os dispositivos de equalização do lugar de interlocução como principal estratégia de construção da legitimidade dos conselheiros. Permitiu também entender melhor a configuração dos lugares de Centro e Periferia e confirmar a circulação como lugar de mediação, transformando os sentidos, agregando ou desagregando valor aos discursos, no caso mediante dispositivos de enunciação de reconhecimento/ legitimação ou negação/ desqualificação.

A pesquisa (2003 a 2007) contou com apoio do CNPq e recursos da própria Fiocruz.

Antes de encerrar, falemos de um procedimento metodológico que estamos desenvolvendo, mencionado aqui anteriormente e que tem se mostrado muito produtivo nestas e em várias pesquisas: o mapeamento de fontes $e$ fluxos da comunicação, que dá concretude metodológica aos conceitos de comunidades discursivas e polifonia, mercado simbólico e concorrência discursiva, centro e periferia. Trata-se do desenho, feito a partir de levantamento de campo, em processos participativos ou não, de uma rede de comunidades discursivas que produzem e fazem circular discursos sobre um determinado tema, direcionado a um determinado segmento da população, num determinado espaço institucional ou geográfico. A idéia de rede permite pôr em cena as múltiplas articulações entre as instâncias materiais - as comunidades discursivas - e as simbólicas seus discursos, sempre tendo como parâmetro as posições de Centro e Periferia. Este procedimento, ao permitir a caracterização de um mercado simbólico específico, facilita a análise discursiva, além de permitir, no âmbito de uma ação prática, um melhor planejamento estratégico da comunicação.

No atual momento, o Laces está desenvolvendo uma pesquisa em âmbito nacional ${ }^{5}$ que tem por objetivos atual- izar o diagnóstico sobre a comunicação praticada no SUS, identificar suas matrizes teóricas e definir um conjunto de indicadores para avaliação da comunicação no campo das políticas públicas. Também estão sendo conduzidas duas teses de doutorado e uma dissertação de mestrado.

\section{Fronteira}

Apreciamos denominar a conclusão de um texto de Fronteiras, pela propriedade de lugar de cruzamento entre o que já foi visto, falado, constituído e o que está por vir. Poderíamos chamá-lo de um "entrelugar" (BHABHA, 1998), um espaço de mediação entre o escrito e o que resultará da sua leitura. Um lugar que expressa interesse e demanda interlocução.

Sobre esse texto, incidirão leituras, a primeira de todas as mediações que produzem realidades de interface. Ler é reescrever o texto em nossas próprias vidas, diz um princípio barthesiano. Esta reflexão, que aponta para as apropriações e novos sentidos que serão produzidos a partir da leitura do texto, pode ser aplicada à atividade de pesquisa do Laces.

Nosso esforço tem sido dirigido, como procuramos aqui mostrar, para a compreensão da realidade da prática comunicativa no campo da saúde. Mas, esta realidade é mediada pelo nosso olhar, portanto já expressa um modo de apropriação e já constitui em si uma realidade de interface.

Tendo esta compreensão como pano de fundo, queremos dizer que as questões que nos mobilizam são antecedidas e pautadas por duas outras: como seguir articulando teorias e métodos que nos ajudem a tornar este mundo mais traduzível, considerando suas diferenças, heterogeneidades e relações de poder? E como essa compreensão do mundo social pode fortalecer os setores em desvantagem nas relações de poder (no âmbito do SUS, das instituições ou da sociedade em geral), no sentido da conquista de um protagonismo político?

O desafio não é pequeno, do ponto de vista metodológico, começando pelo fato de que operamos num espaço lacunar: os dados que se dispõe sobre as pessoas e seus múltiplos contextos não são adequados nem suficientes para dar conta do mercado simbólico e da intensa negociação de sentidos. Mas a principal tarefa é mesmo o desenvolvimento de procedimentos de pesquisa que correspondam às nossas perspectivas teóricas: alguns conceitos ainda exigem tradução metodológica.

Antes de terminar, reiteramos que o Laces é um coletivo, formado por muitas pessoas, que imprimem múltiplos sentidos ao nosso trabalho. Por outro lado, vem agregando novos pesquisadores, portanto, o que aqui foi apresentado não esgota as abordagens teóricas e metodológicas que atualmente obtêm sua tradução em pesquisas e outros trabalhos em curso.

Por fim, se fôssemos propor uma palavra que resumisse o tema deste artigo, seria entre. E, num jogo intertextual, poderíamos falar em interesse. Bourdieu (1997) nos lembra, a partir de remissões a Hanna Arendt, de um sentido possível para a palavra interesse: estar 
entre (inter-esse). Ter interesse significaria participar, dar importância a um "jogo" social, acreditar que vale a pena jogar e que os alvos merecem ser perseguidos. Neste sentido, aqui apresentamos nosso interesse, acreditamos que vale a pena o trabalho que fazemos no Laces. Esse inter-esse, trazemos aqui a público, em busca da sempre desejada interlocução.

\section{Notas}

1. Esta concepção foi sistematizada e proposta como um modelo de comunicação para políticas públicas, denominado Modelo do Mercado Simbólico, na tese de doutorado da autora (ARAÚJO, 2002).

2. A denominação conferida por Milton Pinto ao método que desenvolveu é Análise de Discursos Sociais. Por acreditar que todos os discursos são sociais e para distinguir essa modalidade de $\mathrm{AD}$ da análise meramente lingüística ou textual, optamos pela denominação Análise Social dos Discursos.

3. Os principais expoentes da vertente francesa são Michel Pêcheux e Michel Foucault, na França e no Brasil, Eni Orlandi e seu grupo de pesquisa que se articula em torno do Instituto de Estudos Lingüísticos, da Unicamp. A abordagem associa lingüística e história, com ancoragens no estruturalismo e entende que é função das ideologias a produção e reprodução dos sentidos sociais. A vertente anglo-americana está fortemente vinculada ao empirismo e a conceitos da psicologia do consciente, entendendo que toda fala é uma forma de ação, porém uma ação plenamente consciente, entendendo a comunicação como uma forma de ação cooperativa. Tem na sua origem Ludwig Wittgenstein, com Erwin Goffman, Harold Garfinkel, William Labov, entre os nomes que se destacaram em suas pesquisas. Para um aprofundamento dessas diferenciações, pode ser consultado o livro de Milton Pinto, Comunicação e Discurso (1994), no qual essa nota está baseada.

4. As Conferências integram a estrutura de gestão participativa Sistema Único de Saúde-SUS, são organizadas desde a base municipal e os conselheiros são delegados escolhidos em processo intensamente disputado.

5. Políticas e práticas de comunicação no SUS: mapeamento, diagnóstico e metodologia de avaliação. Apoio financeiro do CNPq.

\section{Referências bibliográficas}

ALBERT, B. O ouro canibal e a queda do céu: uma crítica xamânica da economia política da natureza. Brasília: Ed. UnB, 1995. Série Antropologia.

ARAUJO, I. S. A reconversão do olhar: prática discursiva e produção dos sentidos na intervenção social. São Leopoldo: Ed. Unisinos, 2000.

ARAUJO, I. S. Mercado Simbólico: interlocução, luta, poder. Um modelo de comunicação para políticas públicas. 2002. 352 f. Tese (Doutorado em Comunicação e Cultura) - Escola de Comunicação, Universidade Federal do Rio de Janeiro, Rio de Janeiro.
ARAUJO, I. S. Mercado Simbólico: um modelo de comunicação para políticas públicas. Interface: comunicação, saúde, educação. Fundação UNI/Unesp, v.8, n. 14, set.2003-fev.2004. Botucatu, SP. p.165-78.

ARAUJO, I. S. O mapa da comunicação e a rede de sentidos da saúde. In: PINHEIRO, R. e MATTOS, Ruben A. (Org.) Gestão em redes: práticas de avaliação, formação e participação na saúde. Rio de Janeiro: CEPESC, 2006. p.427-44.

BAKHTIN, M. Marxismo e filosofia da linguagem. São Paulo: Hucitec, 1988.

BENVENISTE, E. O aparelho formal da enunciação. In: . Problemas da lingüística geral II. São Paulo: Pontes, 1989. p. 81-90.

BOURDIEU, P. O poder simbólico. Lisboa: Difel, 1989.

BOURDIEU, P. Razões práticas: Sobre a teoria da ação. Campinas: Papirus, 1997.

BHABHA, H. K. O local da cultura. Belo Horizonte: Editora UFMG, 1998.

CANCLINI, N. G. Noticias recientes sobre la hibridación. In: HOLLANDA, H. B. e RESENDE, B. (orgs.) Artelatina: cultura, globalização e identidades. Rio de Janeiro: Aeroplano, 2000. p. 60-82.

FOUCAULT, M. Microfísica do poder. Rio de Janeiro: Graal, 1982.

LEFÈVRE, F; LEFÈVRE, A. O discurso do sujeito coletivo: um enfoque em pesquisa qualitativa (desdobramentos). Caxias do Sul: Educs, 2003.

LANDOWSKI, E. A sociedade refletida - Ensaios de Sociossemiótica. São Paulo: Pontes, 1992.

MAINGUENEAU, D. Novas tendências em análise do discurso. Campinas: Pontes, 1993.

MARTÍN-BARBERO, Jésus. De los medios a las mediaciones: Comunicación, cultura y hegemonia. Barcelona: Gustavo Gilli, 1993.

OROZCO GÓMEZ, Guillermo. La investigación en comunicación desde la perspectiva cualitativa. GuadalajaraMéxico: IMDEC, 1997.

PÊCHEUX, M. O discurso: estrutura ou acontecimento? Campinas: Pontes, 1990.

PINTO, M. J. As marcas lingüísticas da enunciação: esboço de uma gramática enunciativa do português. Rio de Janeiro: Numen, 1994.

PINTO, M. J. Comunicação \& Discurso: introdução à Análise de Discursos. São Paulo: Hacker Editores, 1999.

TORO, B. Mobilização social: uma teoria para a universalização da cidadania. In: MONTORO, T. S. (Coord.). Comunicação e mobilização social. Série Mobilização Social, vol. 1. Brasília: UnB, 1996. p. 26-40.

VERÓN, E. A produção do sentido. São Paulo: Cultrix, 1980. 


\section{Sobre o autor}

\section{Inesita Soares de Araújo}

Inesita Soares de Araújo possui graduação em Comunicação Social pela Universidade Federal de Pernambuco, mestrado e doutorado em Comunicação e Cultura pela Universidade Federal do Rio de Janeiro. É pesquisadora da Fundação Oswaldo Cruz, membro do Laboratório de Pesquisa em Comunicação e Saúde do CICT/Fiocruz, membro do GT Comunicação e Saúde da Associação Brasileira de Pós-Graduação em Saúde Coletiva, líder do grupo de pesquisa Comunicação e Saúde (CNPq) e membro do Núcleo de Pesquisa em Estratégias de Comunicação da Universidade Federal do Rio de Janeiro. Sua área de experiência e interesse é Comunicação e Políticas Públicas, com especial ênfase no campo da Saúde Coletiva. Principais temas de interesse: políticas e práticas de comunicação e saúde, desenvolvimento metodológico e estratégias de comunicação. 